T. Hirai, et al., SOFT2006 manuscript, ver8

\title{
R\&D on full tungsten divertor and beryllium wall for JET ITER-like Wall Project
}

T. Hirai ${ }^{1}$, H. Maier ${ }^{2}$, M. Rubel ${ }^{3}$, Ph. Mertens $^{1}$, R. Neu ${ }^{2}$, E. Gauthier ${ }^{4}$, J. Likonen ${ }^{5}$, C. Lungu ${ }^{6}$, G. Maddaluno $^{7}$, G. F. Matthews ${ }^{8}$, R. Mitteau ${ }^{4}$, O. Neubauer ${ }^{1}$, G. Piazza ${ }^{9}$, V.Philipps ${ }^{1}$, B. Riccardi ${ }^{7}$, C. Ruset ${ }^{6}$, I.Uytdenhouwen ${ }^{10}$ and JET EFDA contributors

1 Forschungszentrum Jülich, Euratom Association, Jülich Germany

2 Max-Planck-Institut für Plasmaphysik, Euratom Association, Garching Germany

3 Royal Institute of Technology, Association Euratom-VR, Stockholm Sweden

4 Association Euratom-CEA, Cadarache, DSM/DRFC, Saint-Paul-lez-Durance France

5 Association EURATOM-Tekes, VTT, Espoo, Finland

6 National Institute for Laser, Plasma and Radiation Physics, Association Euratom-MEdC,

Bucharest, Romania

7 Association Euratom-ENEA, Frascati, Italy

8 Association Euratom-UKAEA, Culham Science Centre, Abingdon, UK

9 EFDA-Close Support Unit, Culham Science Centre, Abingdon, UK

10 SCK•CEN, The Belgian Nuclear Research Centre, 2400 Mol, Belgium / Ghent University,

Ghent, Belgium

\begin{abstract}
The ITER reference materials have been tested separately in tokamaks, plasma simulators, ion beams and high heat flux test beds. In order to perform a fully integrated material test JET has launched the ITER-like Wall Project with the aim of installing a full metal wall during the next major shutdown. As a result of $R \& D$ projects in 2005-2006, bulk tungsten tiles are foreseen at the outer horizontal target and tungsten coating at the other divertor tiles. In some regions of the main chamber, beryllium coated Inconel tiles and bulk beryllium tiles are utilised which include marker tiles as erosion diagnostics. This paper gives an overview of the R\&D carried out in the frame of the ITER-like Wall Project on the development of an inertially cooled bulk tungsten tile design and the characterization of tungsten and beryllium coating technologies.
\end{abstract}

Key words: tungsten, beryllium, coating, JET, ITER-like, high heat flux test

PACS: 28.52.Fa, 28.52.Lf, 52.40.Hf, 07.20.Ka, 81.15.-Z 


\section{Introduction - the ITER-Like Wall Project}

Currently, the primary ITER material choice is beryllium $(\mathrm{Be})$ for the entire main chamber wall, carbon fibre composite (CFC) at the divertor strike points and tungsten (W) on the baffles and dome (fig. 1a). These ITER reference materials have been tested separately in tokamaks, plasma simulators, ion beams and high heat flux test beds [1]. However, an integrated test demonstrating both compatibility of metal plasma facing components (PFC) with high-power operation and acceptable tritium retention has not yet been carried out. At JET, it is possible to test the full combination of ITER wall materials. In JET the size, magnetic field strength and high plasma current make it possible to conduct tests at the most ITER-relevant parameters accessible today. The ITER-like Wall (ILW) project [2-4] has been launched to design, manufacture and test all the necessary components in view of their installation in a dedicated shutdown.

The objective of the ILW Project is to install in JET beryllium PFC in the main chamber and an $\mathrm{W}$ divertor (the favoured back-up materials solution for ITER, fig. 1b, fig. 2). The chosen material configuration is technically more demanding, but gives a clearer physical case than the ITER-reference combination with CFC tiles at the strike point. It also opens the option to replace specific rows of divertor tiles with CFC at a future date. The ILW Project will be a test bed for integrated scenarios with ITER-relevant edge conditions and compatibility with the wall thus providing essential information for the next-step devices.

This paper gives an overview of R\&D projects launched in the frame of the ILW Project for the $\mathrm{W}$ divertor (both $\mathrm{W}$-bulk and $\mathrm{W}$-coated tiles), and the development of Be coating and marker tiles.

\section{Bulk Tungsten}

\subsection{Tungsten lamellae divertor tile design}

A crucial step in the preparatory phase of the ILW is the development of a concept for the outer horizontal divertor plate (see fig. 2), so-called load-bearing septum replacement plate. This PFC has to withstand heat fluxes of up to $7 \mathrm{MW} / \mathrm{m}^{2}$ for $10 \mathrm{~s}$ (swept configurations). Owing to the brittleness of $\mathrm{W}$, only a "castellated" design is thought to withstand high temperature gradients in cyclic operation. A rough estimate gives operational temperatures of $1200^{\circ} \mathrm{C}$ on the top surface with possible peak temperatures up to $2200^{\circ} \mathrm{C}$ keeping the margin of temperature increase $\left(\sim 800^{\circ} \mathrm{C}\right)$ during ELM-events. At the same time, the temperature at the bottom of the component should not exceed $500-700^{\circ} \mathrm{C}[\mathbf{5 , 6}]$ because of the temperature limit 
of metallic fittings made of Inconels $\left(<700{ }^{\circ} \mathrm{C}\right)$. The design values require the component to withstand $10 \mathrm{MW} / \mathrm{m}^{2}$ for $10 \mathrm{~s}$, corresponding to the divertor phase of a tokamak pulse. Two solutions have been considered: (i) an assembly of W blades (lamellae) and (ii) a design with W blocks brazed to a CFC body (a back-up solution). The lamellae-type tile has been developed with high priority. It consists of stacks of W blades (four of them per tile and two tiles per module), mounted onto a supporting structure, called "wedge". This component had to be designed completely from scratch because the previous supporting structure could not cope with high electromagnetic forces expected when such a fully metallic tile is exposed both to high toroidal magnetic field (4 $\mathrm{T}$ at the centre of the machine) and high poloidal magnetic filed variations (up to $100 \mathrm{~T} / \mathrm{s}$ ) and halo current ( 20 kA/module) during disruptions. The developed wedge is shown in fig. 3 (only one half is shown with the $\mathrm{W}$ lamellae in place). The whole concept has been determined by electromagnetic considerations: (i) to minimize eddy currents by cutting conducting loops as far as possible, and (ii) to provide a well-defined path for halo currents: down to the JET base plate. The first objective should be attained through deep cuts between wedge "wings" as seen on the left side of fig. $\mathbf{3}$ and adequate electrical insulation using $\mathrm{ZrO}_{2}$ coatings between the $\mathrm{W}$ blades and supporting wedge. The second condition is fulfilled by direct connection of the tiles to the base plate through the four feet per tile. A high mechanical pre-loading of the long bolts that assemble the lamellae stacks together is desirable, with regard to the differential thermal expansion of W plus TZM (chosen for the spacers between $\mathrm{W}$-blades) versus the metallic tie rods. The vertical electromagnetic pull is high, estimated at more than $4 \mathrm{kN}$ per tile $(\sim 1.3 \mathrm{kN}$ per stack) [6 - 8].

To specify preferable $\mathrm{W}$ grades for the blade, mechanical properties and re-crystallization resistance of various grades have been examined in SCK-CEN, Mol. As a result, sintered and rolled grades were recommended. In parallel, electron beam welding of W/TZM has been studied at CEA Cadarache and FZJ Jülich as an alternative lamellae blade concept with W plasma facing surface and TZM body.

\subsection{High-heat flux testing of bulk tungsten tiles}

High-heat flux (HHF) tests were performed in the electron beam facility JUDITH, FZJ Jülich [9]. No macroscopic damage was observed up to $156 \mathrm{MJ} / \mathrm{m}^{2}\left(7.8 \mathrm{MW} / \mathrm{m}^{2}\right.$ for $\left.20 \mathrm{~s}\right)$ in W components. This is well above the requirement. In the tests of material durability (failure test) $9 \mathrm{MW} / \mathrm{m}^{2}$ was applied for $15 \mathrm{~s}$ leading to surface temperatures above $2500^{\circ} \mathrm{C}$. Micro-cracks were observed at the loaded surface. The impact of micro-cracks on the performance seemed to 
be negligible for this degree of cyclic thermal loading, 7 8 MW/m² for $10 \mathrm{~s}$ up to $\sim 150$ cycles, since no significant temperature increase was observed $[\mathbf{1 0}]$. The lamellae concept was also exposed to fusion plasma (in TEXTOR tokamak at FZ Jülich) to confirm both the design feasibility and the options in blade size, gap width, shaping of the top surface, and electrical insulation schemes. The deposited power was above the critical threshold onto the test tile in a tokamak discharge and part of the tile melted under a critical power loading. Due to the melting, W top surface was tapered in a round shape. However, no other damage was observed. Electric insulation made of $\mathrm{Al}_{2} \mathrm{O}_{3}$ coating kept sufficient resistivity after the exposure. It proved that $1 \mathrm{~mm}$ groove in the design concept was large enough to prevent the bridging of the two blades under those operation conditions.

Due to the successful outcome of the bulk W tile R\&D the design was accepted for inclusion in the procurement phase of the ILW Project.

\section{Tungsten coatings}

\subsection{Tungsten-coated CFC}

To minimize both design and procurement costs, $\mathrm{W}$ coatings have to be applied onto tiles made of a two-directional CFC (the existing design). Due to the anisotropic properties of the CFC and the mis-match of thermal expansion coefficients between CFC and W, thermomechanical issues become critical [11]. Therefore, sufficient effort has been spent to examine a variety of coating deposition processes (Vacuum Plasma Spray (VPS), Chemical Vapour Deposition (CVD), Physical Vapour Deposition (PVD)) and coating thickness (4 $\mu \mathrm{m}, 10 \mu \mathrm{m}$ and $200 \mu \mathrm{m})[\mathbf{1 2}]$. R\&D was performed at five EURATOM Associations: CEA Cadarache, ENEA Frascati, IPP Garching, MEdC Bucharest with support from CEA Cadarache, and TEKES Espoo. After the R\&D activity in 2005, the Associations delivered their optimized coatings to IPP Garching. The W coatings were created on specially designed test coupons of CFC incorporating features of actual JET divertor tiles (fig. 4). Most of the coatings were deposited at surfaces perpendicular to the fibre planes.

\subsection{Qualification of tungsten coatings}

At IPP Garching all coating types were subjected to a thorough screening that involved metallography, chemical analysis and HHF tests [12]. The main part of the test programme was a HHF tests in the ion beam facility, GLADIS [13]. The first step consisted of a thermal 
screening test, i.e. step-wise increase of power density and pulse duration to determine the ultimate performance limits of the individual coatings. This was conducted up to a central power density of more than $23 \mathrm{MW} / \mathrm{m}^{2}$, which led to peak surface temperatures in excess of $2000^{\circ} \mathrm{C}$ after a pulse duration of $1.5 \mathrm{~s}$. Secondly, thermal fatigue tests were performed by cyclic heat loading. This test was considered to be of great importance since the thermal expansion mis-match could lead to fatigue phenomena. HHF cycles, up to 200 pulses of $10.4 \mathrm{MW} / \mathrm{m}^{2}$ for $5 \mathrm{~s}$ led to the development of tensile cracks in the coatings. These occurred in the no-reinforced direction of the CFC material, in which the thermal expansion of the substrate was smaller than that of the $\mathrm{W}$ coatings where the coatings had become stress-relaxed at high temperature and experienced compression upon cool-down. Moreover, it was found that the stiffness of the W films is insufficient, if it is restricted to the micrometer range. Upon repeated compressive stress this insufficient stiffness leads to instability against delamination and buckling (fig. 5a). This is accompanied by fatigue cracks. This was observed for $4 \mu \mathrm{m}$ and $10 \mu \mathrm{m}$ coatings after cyclic loading, except for the $10 \mu \mathrm{m} \mathrm{W}$ coating with molybdenum interlayer supplied by MEdC Bucharest. The coating was produced by a combination of magnetron sputtering deposition and simultaneous ion implantation for relaxation of compressive stress. The excessive compressive stress during the $\mathrm{W}$ deposition processes was pointed out in the previous studies [14]. The third heat load qualification step was performed in the JUDITH facility, where ELM-like pulses of $0.35 \mathrm{GW} / \mathrm{m}^{2}, 1 \mathrm{~ms}$ were applied for 1000 pulses. In this test, the $200 \mu \mathrm{m}$ coatings were found to be stable (fig. 5b).

\subsection{Selection of tungsten coatings for the JET divertor and main chamber}

The analysis of $3 \mu \mathrm{m}$ thick $\mathrm{W}$ marker stripes from the previous JET experimental campaign suggests that thin coatings $(10 \mu \mathrm{m})$ have a marginal erosion lifetime for the outer strike point. High erosion was also seen on the horizontal section of the divertor baffle so a 200 $\mu \mathrm{m}$ VPS coating and a bulk $\mathrm{W}$ tile row are proposed for the outer divertor. The inner divertor is a strong deposition zone and the $3 \mu \mathrm{m} \mathrm{W}$ stripes appeared intact under a thick layer of Be and C. However, due to concerns about Be/W alloying a $200 \mu \mathrm{m}$ VPS W coating is proposed here as well (fig. 2). Since some of the tested $200 \mu \mathrm{m}$ coatings displayed local failures, it was decided that a test at a moderate heat flux tests is mandatory for each individual tile before installation in JET. This will be performed at the JUDITH II facility [15] in FZJ Jülich with support from IPP Garching on the quasi-real-time data processing. 
In the recessed areas of the main chamber (e.g. NBI shinethrough protection), $10 \mu \mathrm{m} \mathrm{W}$ coatings are expected to have sufficient erosion lifetime due to lower sputtering and to pose a lower disruption risk in the event of flaking. The coating type, which will be applied there, is the one mentioned above, produced by the Association MEdC Bucharest. A facility for mass production of this coating type will be constructed and commissioned in Bucharest.

\section{R\&D on beryllium coating}

The material foreseen for the main chamber wall is bulk Be at the limiters [2] and Be coatings on inconel tiles elsewhere. Activities related to the development of coatings are ongoing in two areas: (a) protective layers on Inconel tiles to ensure reduced influx of impurities by full coverage of the wall with low-Z material; (b) marker films on bulk Be tiles for the assessment of erosion rates in the main chamber of JET.

\subsection{Beryllium coatings on Inconel}

Inconel tiles of the inner wall and dump plate will be coated with a 7-9 $\mu \mathrm{m}$ thick film deposited by Be evaporation performed in the Nuclear Fuel Factory, Pitesti, Romania. R\&D process comprises global characterisation (structure, purity etc) of the evaporated films and testing of their performance under heat loads. The tests carried out in the JUDITH facility aimed at the assessment of the performance under: (a) a screening test to determine the energy density causing damage, (b) a power cycling at the energy level typically deposited onto the cladding during the regular operation of JET: $0.5 \mathrm{MW} \mathrm{m}^{-2}$ for $10 \mathrm{~s}$, corresponding to $5 \mathrm{MJ} \mathrm{m}^{-2}$. The coatings are of high purity and the presence of oxygen is detected in a thin outermost layer [16]. It also adheres well to the substrate, and no exfoliation has been observed during longterm storage in air. HHF tests proved that the layer survived undamaged power loads of up to $2.6 \mathrm{MW} \mathrm{m}{ }^{-2}$ in $6.2 \mathrm{~s}$ (deposited energy density of $18.1 \mathrm{MJ} \mathrm{m}^{-2}$ ) thus exceeding significantly the required level of $5 \mathrm{MJ} / \mathrm{m}^{2}$ [17]. This qualifies the evaporation process to be used for the coating of large areas of the JET vessel inner wall.

\subsection{Marker layers for beryllium smart tiles}

An important goal of the ILW Project and its contribution to ITER is to assess the Be erosion from the main chamber plasma-facing components. For that purpose marker tiles will be used. Several solid Be tiles will be coated with a higher- $\mathrm{Z}$ metal interlayer (2-3 $\mu \mathrm{m})$ and 7-8 
$\mu \mathrm{m}$ Be film. This will allow erosion measurements up to this depth, whereas for assessing a greater erosion than that the tiles will have precise notches of 10 and $20 \mu \mathrm{m}$ depth. More details on the application of marker tiles can found elsewhere $[\mathbf{1 8}, \mathbf{1 9}]$. The Be marker layer must adhere to the substrate and be sufficiently compact to resemble bulk $\mathrm{Be}$ in order to make the measurements conclusive. Thermionic Vacuum Arc (TVA) technique based on electroninduced evaporation [20] has been selected for this purpose. The deposition has been optimised and the composition of the interlayer has been chosen after carrying out tests with nickel, tungsten, and rhenium. Nickel, which was the primary choice, has been selected because of the close values of linear thermal expansion coefficients at room temperature for $\mathrm{Ni}\left(13 \times 10^{-6} \mathrm{~K}^{-1}\right)$ and $\mathrm{Be}\left(16 \times 10^{-6} \mathrm{~K}^{-1}\right)$. The coefficients for the other candidates are significantly lower $\left(4.5 \times 10^{-6}\right.$ $\mathrm{K}^{-1}$ for $\mathrm{W}$ and $6.6 \times 10^{-6} \mathrm{~K}^{-1}$ for $\mathrm{Re}$ ), thus creating a risk of layer flaking under heat loads. Testing of the marker layer performance under power loads in JUDITH is the next step in the process of material qualification. In parallel, the erosion behaviour of the coatings (both markers and films deposited on cast Inconel) by high fluxes of deuterium plasma will be studied in PISCES-B, a Be compatible simulator of plasma-wall interactions [21].

\section{Concluding remarks}

The ILW Project selected the full W divertor option. As a result of the R\&D project, bulk W tiles will be employed for the outer divertor strike point target and $200 \mu \mathrm{m}$ VPS-W coating produced by an industrial supplier on the rest of divertor surfaces. The procurement procedures have been launched. The installation of the new plasma facing components is scheduled in a dedicated shutdown in 2009. The $10 \mu \mathrm{m}$ PVD-W coating will be applied to the main chamber CFC tiles. The mass production facility for the coating is now under preparation in MEdC Bucharest. A Be coating $(7-9 \mu \mathrm{m})$ on a cast Inconel tiles was tested under heat flux and showed excellent performance, above the required power density. The Be coating will be used for the large Inconel surface of the JET vessel wall. To assess the Be erosion from the main chamber plasma-facing components, marker tiles are under development and will be tested under HHF and high deuterium flux loading in 2006.

\section{Acknowledgements}

This work, supported by the European Communities under the contract of Association between EURATOM/FZJ, was carried out within the framework of the European Fusion Development 
Agreement. The views and opinions expressed herein do not necessarily reflect those of the European Commission.

\section{References}

[1] T. Hirai, K. Ezato, P. Majerus, Materials Transactions, 46 (2005) 412-424.

[2] G. F. Matthews, T.Hirai, A.Lioure, A.Loving, H.Maier, J.Pamela, V.Philipps, G.Piazza, V.Riccardo, M.Rubel, E.Villedieu for the ITER-like Wall Project Team, "ITER-like Wall Project Overview", to be presented in PFMC-11, Greifswald Germany, October 2006.

[3] J. Pamela, et al., “An ITER-like Wall for JET”, presented at 17th international conference on plasma surface interaction in controlled fusion devices, Hefei China, 22-26 May 2006.

[4] G. Piazza, G. F. Matthews, J. Pamela, H. Altmann, J. P. Coad, T. Hirai, A. Lioure, E. Villedieu, H. Maier, P. Mertens, V. Philipps, M. Rubel and collaborators of the JET ITERlike Project, "The ITER-like Wall Project", presented at ICFRM-12, Santa Barbara US, December 2006.

[5] Ph. Mertens, O. Neubauer, T. Hirai, "Development of a bulk tungsten divertor plate for the JET tokamak", the proceedings of Annual meeting on nuclear technology, Aachen Germany, May 2006.

[6] Ph. Mertens, T. Hirai, O. Neubauer, V. Philipps, S. Sadakov, U. Samm, B. Schweer, JETEFDA contributors, "Conceptual design for a bulk tungsten divertor tile in JET", in these proceedings.

[7] S. Sadakov, Ed. Bondarchuk, N. Doinikov, T. Hirai, B. Kitaev, N. Ozhukhovskaya, I. Maximova, Ph. Mertens, O. Neubauer, "Design optimisation of a solid tungsten divertor plate for JET resulting from pure electromagnetic consideration", in these proceedings.

[8] A. Borovkov, A.Gaev, A. Nemov, "3-D finite element coupled field analysis of the JET LB-SRP divertor element", in these proceedings.

[9] R. Duwe, W. Kühnlein and H. Münstermann, Proc. 18th Symposium on Fusion Technology (SOFT), Karlsruhe Germany, (1994) 355-358.

[10] T. Hirai, Ph. Mertens, O. Neubauer, Th. Kopitz, W. Kuehnlein, J. Linke, V. Philipps, G. Pintsuk, S. Sadakov, B. Schweer, I. Uytdenhouwen, U. Samm and R. Sievering, "Development and testing of a bulk tungsten tile for the JET divertor", to be presented in PFMC-11, Greifswald Germany, October 2006.

[11] H. Maier, Materials Science Forum 475-479 (2005) 1377-1382.

[12] H. Maier, R. Neu, H. Greuner, Ch. Hopf, G. F. Matthews, G. Piazza, T. Hirai, G. Counsell, X. Courtois, R. Mitteau, E. Gauthier, J. Likonen, G. Maddaluno, V. Philipps, B. Riccardi, C. Ruset, EFDA-JET Team, "Tungsten coatings for the JET ITER-like Wall Project", presented at 17th PSI conference, Hefei China, May 2006.

[13] H. Greuner, H. Bolt, B. Böswirth, T. Franke, P. McNeely, S. Obermayer, N. Rust, R. Süß, Fusion Eng. Des. 75-79 (2005) 345-350.

[14] H. Maier, J. Luthin, M. Baden, J.Linke, F.Koch, H. Bolt, Surface and Coatings Technology 142-144 (2001) 733-737. 
[15] P. Majerus, T. Hirai, J. Linke, W. Kühnlein, M. Rödig, R. Duwe, Fusion Design and Eng. 75-79 (2005) 365-369.

[16] C. P. Lungu, I. Mustata, V. Zaroschi, A. M. Lungu, A. Anghel, P. Chiru, M.J. Rubel, J.P.Coad, G.F. Matthewsc and JET-EFDA contributors, "Beryllium Coatings on Metals, Development Process and Characterisation of layers", to be presented in PFMC-11, Greifswald Germany, October 2006.

[17] T. Hirai, J. Linke, P. Sundelin, M. Rubel, W. Kühnlein, E. Wessel, J.P. Coad, C. P. Lungu, G.F. Matthews, L. Pedrick, G. Piazza and JET-EFDA contributors, "Heat Flux Testing and Post-mortem Characterisation of Beryllium Coatings on Inconel", to be presented in PFMC-11, Greifswald Germany, October 2006.

[18] M. Rubel, J.P. Coad, K. Stenström, P. Wienhold, J. Likonen, G.F. Matthews, V. Philipps, Overview of tracer techniques in studies of material erosion, re-deposition and fuel inventory in tokamaks, J. Nucl. Mater.329-333 (2004) 795-799.

[19] J.P. Coad, J. Likonen, M. Rubel, E. Vainone-Ahlgren, D.E. Hole, T. Sajavaara, T. Renvall, G.F. Matthews, Overview of material re-deposition and fuel retention studies at JET with the Gas Box divertor, Nucl. Fusion 46 (2006) 350-366.

[20] C.P. Lungu, I. Mustata, G. Musa, A.M. Lungu, V. Zaroschi, K. Iwasaki, R. Tanaka, Y. Matsumura, I. Iwanaga, H. Tanaka, T. Oi, K. Fujita, Formation of nanostructured Re-CrNi diffusion barrier coatings on Nb superalloys by TVA method, Surf. Coat. Techn. 200 (2005) 399-405.

[21] K. Schmid, M.J. Baldwin, R.P. Doerner, Influence of beryllium plasma seeding on the erosion of carbon, J. Nucl. Mater. 337-339 (2005) 862-866.

\section{Figure captions}

Fig.1 (a) ITER material configuration, and (b) material configuration for the JET ITER-like Wall Project.

Fig. 2 Poloidal cross section of the JET divertor showing the material selection and the magnetic field configuration of an ITER-like plasma shape.

Fig. 3 Bulk W lamellae concept (only one half shown with W lamellae in place)

Fig. 4 Set of W coatings delivered from each association for high heat flux testing.

Fig. 5 (a) SEM images of $4 \mu \mathrm{m}$ coating displaying typical thin coating failures: tensile cracking (vertical cracks) and buckling failure resulting from fatigue cracks after cyclic thermal 
T. Hirai, et al., SOFT2006 manuscript, ver8

tests, (b) $200 \mu \mathrm{m}$ coating showing only tensile cracking after thermal fatigue and ELMlike loading tests. 
T. Hirai, et al., SOFT2006 manuscript, ver8

Figure 1

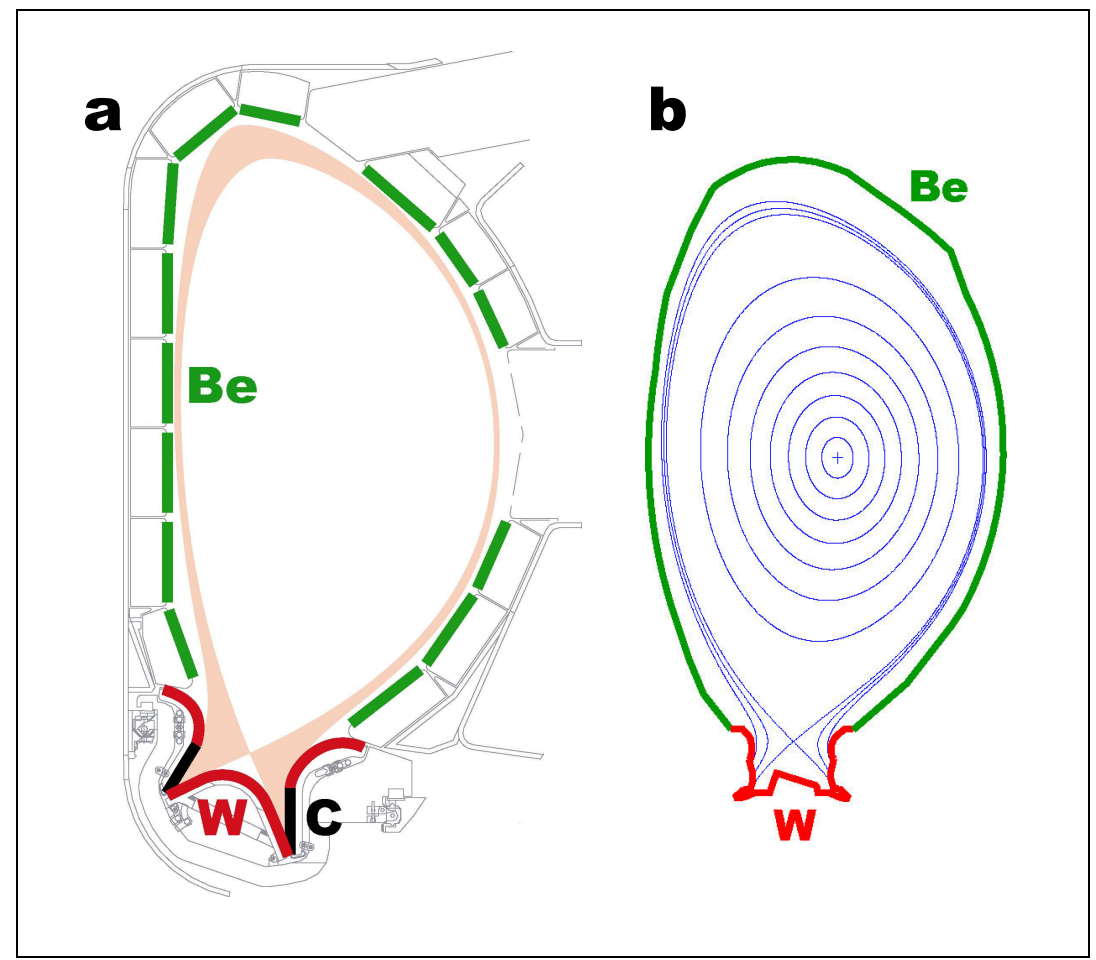

Figure 2

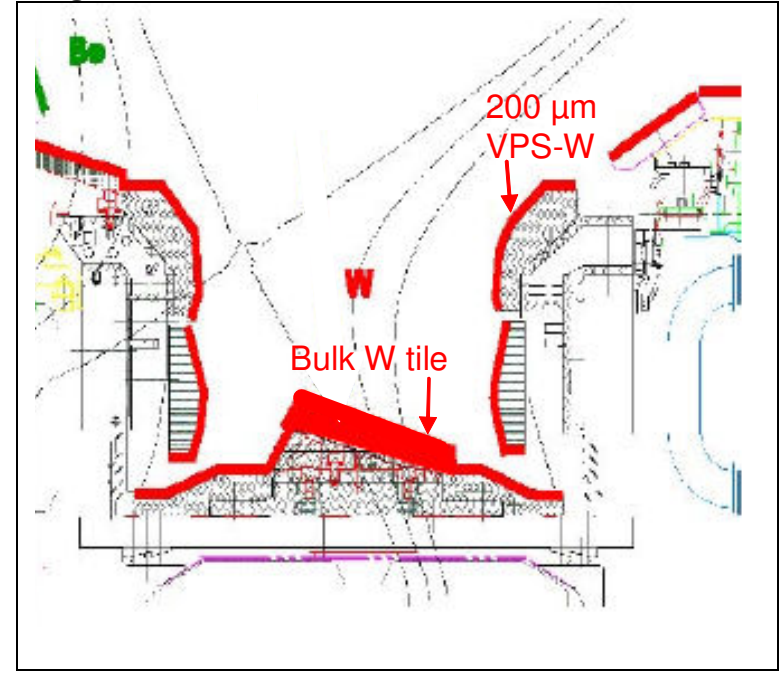


T. Hirai, et al., SOFT2006 manuscript, ver8

Figure 3

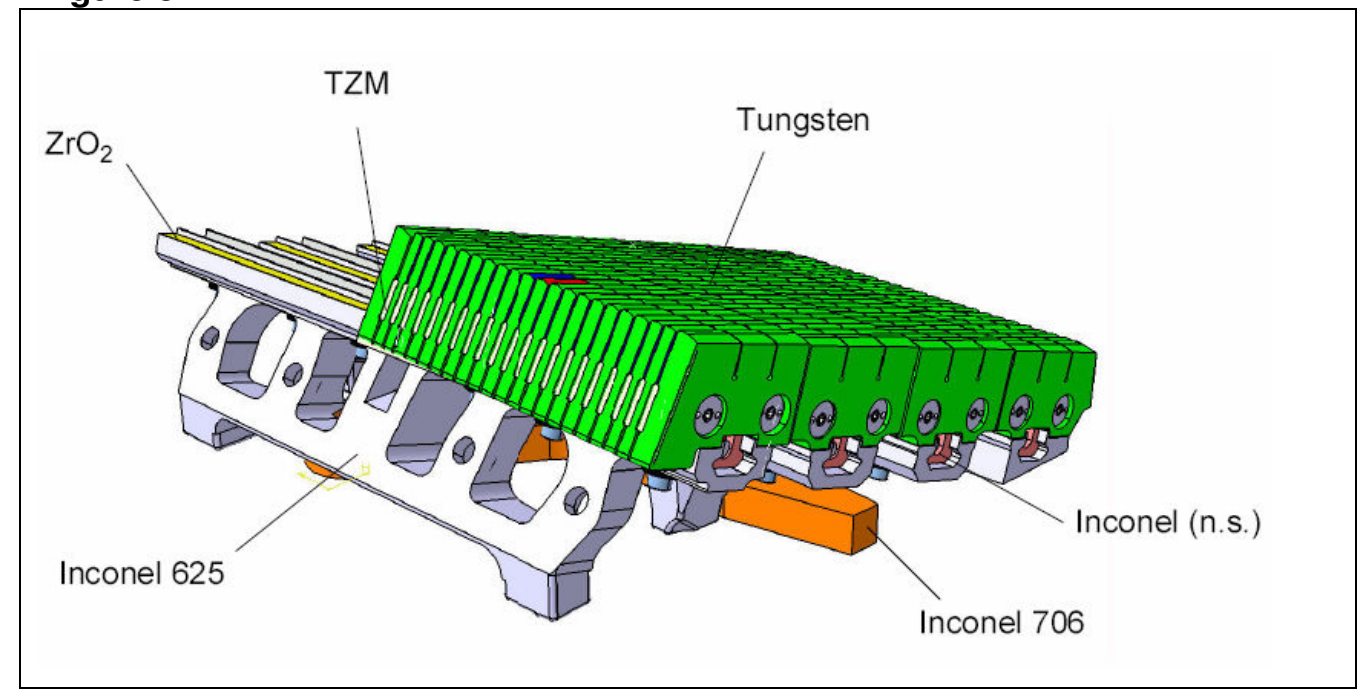

\section{Figure 4}

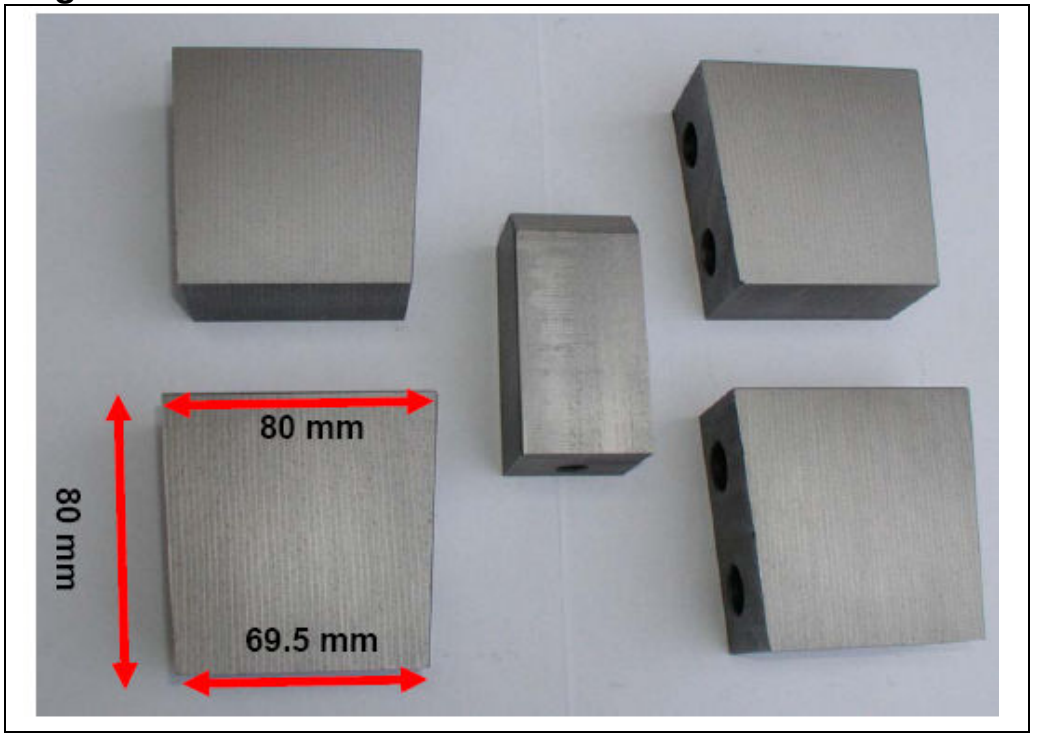


T. Hirai, et al., SOFT2006 manuscript, ver8

Figure 5

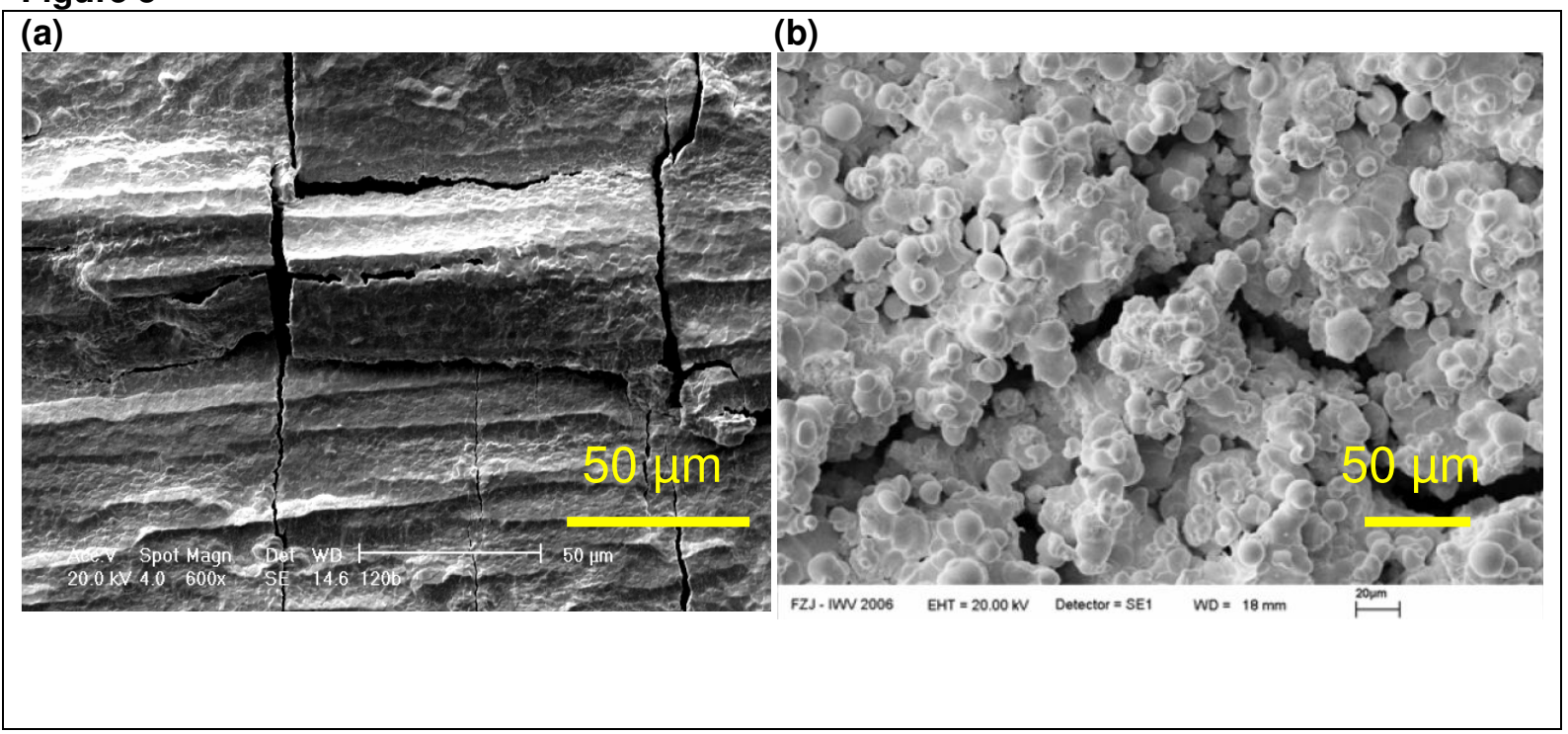

